\title{
PENGARUH LAJU ALIRAN GAS TERHADAP NILAI KEKERASAN BAJA KARBON RENDAH HASIL HARDFACING DENGAN PROSES GTAW
}

\author{
Siska Titik Dwiyati, Ferry Budhi Susetyo, A.Daniel Pandu Yudhantono \\ Teknik Mesin, Fakultas Teknik, Universitas Negeri Jakarta

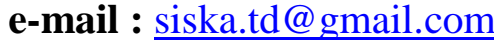

\begin{abstract}
ABSTRAK
Penelitian ini bertujuan untuk mengetahui pengaruh yang terjadi akibat adanya laju aliran gas 1 L/menit, 3 L/menit, dan 5 L/menit terhadap nilai kekerasan baja karbon rendah pada proses GTAW. Berdasarkan hasil penelitian, bahwa laju aliran gas 1 liter/menit menghasilkan nilai kekerasan paling tinggi pada baja karbon rendah yang telah di heat treatment, yaitu sebesar 88 HRB. Laju aliran gas 3 liter/menit pada karbon rendah menghasilkan nilai kekerasan sebesar 83 HRB, sedangkan laju aliran gas 5 liter/menit, menghasilkan nilai kekerasan sebesar 70 HRB. Baja tanpa heat treatment yang dilas dengan laju aliran gas 1 liter/menit menghasilkan nilai kekerasan sebesar 82 HRB. Laju aliran gas 3 liter/menit pada baja tanpa heat treatment menghasilkan nilai kekerasan sebesar 76 HRB, sedangkan laju aliran gas 5 liter/menit menghasilkan nilai kekerasan sebesar 65 HRB.
\end{abstract}

Kata kunci: GTAW, quenching, hardfacing, baja karbon rendah, laju aliran gas

\section{PENDAHULUAN}

Pengelasan merupakan penyambungan dua bahan atau lebih yang didasarkan pada prinsipprinsip proses difusi, sehingga terjadi penyatuan bagian bahan yang disambung. (Purwaningrum, 2006) Selain untuk penyambungan, proses las juga dapat digunakan untuk reparasi, misalnya untuk mengisi lubang-lubang pada coran, membuat lapisan pada perkakas, mempertebal permukaan material dan reparasi lainnya. Pengelasan untuk mempertebal permukaan biasanya banyak digunakan untuk ripper teeth,scoops lift buckets, dozer blades, dll.

Baja merupakan logam yang paling banyak digunakan dalam bidang teknik. Baja merupakan logam paduan, dimana logam besi yang berfungsi sebagai unsur dasar dicampur dengan beberapa elemen lainnya, termasuk unsur karbon. Baja karbon diklasifikasikan menjadi 3, yaitu baja karbon rendah, baja karbon sedang, dan baja karbon tinggi. (Amanto \&Daryanto, 2006)

Baja karbon rendah merupakan baja yang karakteristiknya mudah untuk dijadikan bahan fabrikasi atau konstruksi. Meskipun mempunyai kekerasan yang tidak terlalu tinggi, baja karbon rendah termasuk mudah untuk perlakuan pengelasan. (Wiryosumarto,\& Okumura 2000)Baja jenis ini sering digunakan untuk alatalat berat dan alat-alat pertanian. Namun demikian, seringkali timbul permasalahan dalam penggunaanya, karena jika terus mengalami interaksi dengan benda benda keras lain dan dalam jangka waktu tertentu maka akan menimbulkan keausan. Hal ini tentu saja sangat merugikan karena permasalahan yang muncul tentu akan mempengaruhi umur pemakaian dan merembet pada biaya perawatan yang meningkat, terlebih kalau harus mengganti keseluruhan komponen yang rusak.

Berbagai upaya dilakukan untuk meningkatkan nilai kekerasan. Salah satunya adalah dengan teknik pelapisan permukaan. Teknik ini diaplikasikan dengan tujuan untuk memperkuat lapisan permukaan baja sehingga kerusakan dapat diminimalisir. Salah satu jenis pelapisan permukaan adalah pengelasan hardfacing. (Wiryosumarto,\& Okumura,2000). Hardfacing adalah proses dimana material yang lebih keras diaplikasikan pada suatu material induk melalui proses pengelasan, thermal spraying, ataupun proses penyambungan lainya untuk mengurangi resiko aus dan memperpanjang umur pemakaian. (Saini, \& Singh, 2016)

Meski kekerasan meningkat, tetapi sifat ulet dan ketangguhan material substrat masih tetap terjaga. Hardfacing dengan teknik pengelasan biasanya digunakan untuk meningkatkan umur pemakaian dari komponen mesin baik dengan membangun kembali atau dengan membuat dinding logam yang menahan masalah seperti erosi, korosi, abrasi, dll. Pengerasan pada permukaan melalui metode pengelasan ini dapat mengembalikan komponen dan memperpanjang masa kerja. (Digambar, \& Choudhary, 2014)

Beberapa metode pengelasan seperti shielded metal arc welding (SMAW), gas metal arc welding (GMAW), submerged arc welding (SAW), dan oxyacetylene gas welding (OAW) 
dapat digunakan untuk proses pengelasan hardfacing. (Kenchi Reddy \& Jayadeva, 2012)

Dalam penelitian ini akan membahas mengenai laju aliran gas proses GTAW(Dadang, 2013)terhadap nilai kekerasan dari hasil hardfacing.

\section{PROSEDUR PENELITIAN}

a. Metode Penelitian

Prosedur penelitian digunakan dalam bentuk sketsa seperti terlihat pada gambar

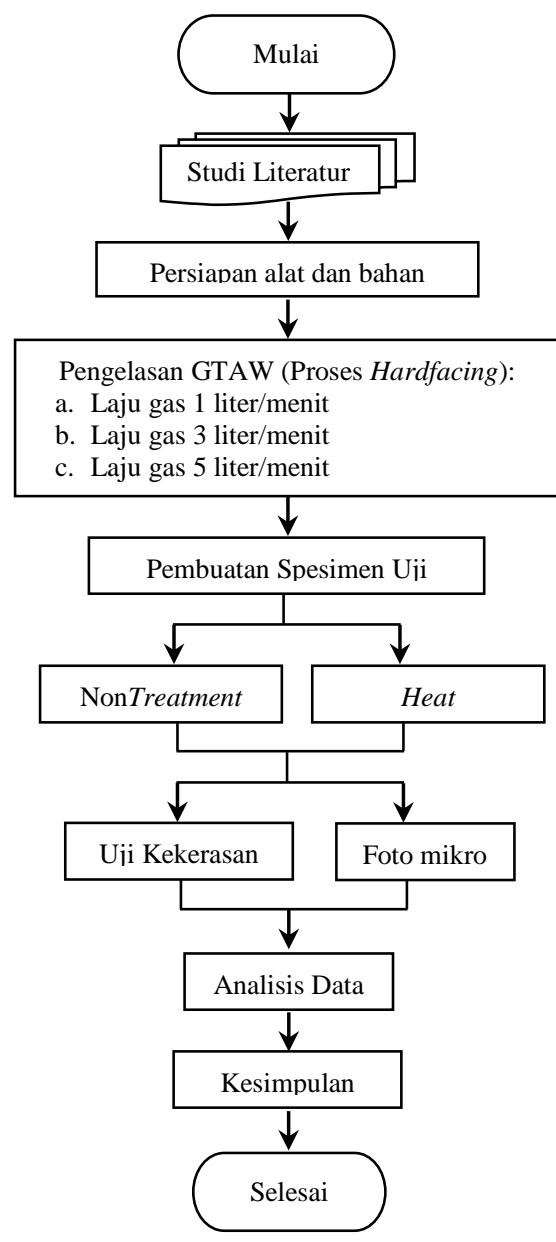

Gambar 2.1. Alur Penelitian

\section{b. Alat dan Bahan Penelitian} ini adalah:

Alat Alat yang digunakan pada penelitian

1. Satu set mesinGTAW/TIG

2. Tang penjepit

3. Gerinda tangan

4. Mesin potong

5. Mesin milling

6. Amplas dengan tingkat kekasaran 100-1500

7. Hair dryer

8. Alat uji kekerasan Rockwell (Eddy, 2014)

9. Perlengkapan K3 Pengelasan
Bahan yang digunakan untuk menunjang pelaksanaan penelitian, yaitu:

1. Baja Karbon Rendah

2. Elektroda HV 600 diameter 2.6 mm (Nikko Steel, 2009)

3. Amplas dengan tingkat kehalusan 100-1500

4. Autosol

5. Larutan Asam Nitrat

6. Air

7. Alkohol

\section{c. PemotonganMaterial Baja}

Langkah pertama adalah memotong lembaran-lembaran baja karbon rendah dengan ketebalan $8 \mathrm{~mm}$ menjadi plat-plat yang lebih kecil dengan ukuran 100 x $65 \mathrm{~mm}$. Pemotongan dilakukan dengan menggunakan cutting gas

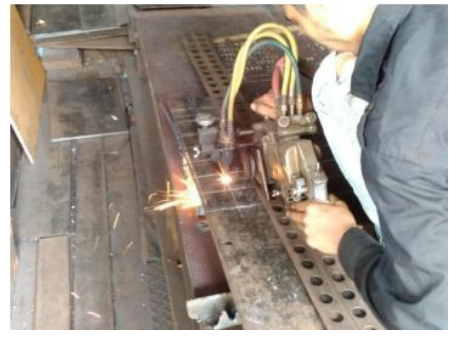

Gambar 2.2. Pemotongan Material

\section{d. Proses Pengelasan}

Setelah didapatkan ukuran plat yang dibutuhkan, maka langkah selanjutnya adalah melakukan pengelasan, dimana pengelasan yang dipilih adalah pengelasan jenis GTAW/TIG. Proses pengelasan menggunakan laju gas yang berbeda, sesuai dengan yang dibutuhkan. Terdapat 3 plat yang dilas dengan laju aliran gas yang digunakan masing 1, 3, dan 5 liter/menit. Pengelasan dilakukan diatas permukaan plat sebanyak 1 layer, sehingga menutupi seluruh permukaan.

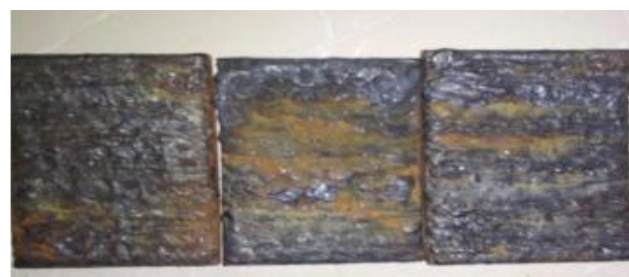

Gambar 2.3 Hasil pengelasan

\section{e. Pembuatan Spesimen Uji Keras}

Langkah selanjutnya adalah memotong plat yang telah dilas mendekati ukuran spesimen pengujian. Pemotongan plat dipotong dengan rincian sebagai berikut:

a. Masing-masing plat yang dilas dengan laju aliran gas berbeda akan dipotong menjadi 
spesimen berukuran $65 \times 20 \mathrm{~mm}$ sebanyak 2 buah.

b. Masing-masing bagian plat yang telah dipotong akan diberikan perlakuan panas ataupun yang tidak.

c. Semua spesimen baik yang diberikan perlakuan panas ataupun tidak, akan dilakukan pengujian keras. Proses pembuatan spesimen uji kekerasan Baja hasil pengelasan dengan ukuran awal 100 x $65 \mathrm{~mm}$ dan ketebalan $12 \mathrm{~mm}$ dipotong menjadi spesimen yang lebih kecil dengan ukuran masing masing $65 \times 20 \mathrm{~mm}$ dengan menggunakan gerinda potong.

Langkah selanjutnya adalah melakukan perlakuan panas terhadap spesimen-spesimen yang telah dipotong. Berikut adalah tahapantahapannya:

a. Menyiapkan spesimen uji sebanyak 3 buah dari masing-masing plat yang berbeda laju aliran gasnya untuk kemudian dipanaskan di dalam tungku dengan suhu $1000^{\circ} \mathrm{C}$ dengan holding time 60 menit.

b. Setelah diberikan perlakuan panas, kemudian dilakukan pendinginan cepat dengan media air (quenching)

\section{f. Pembuatan Spesimen untuk Foto Mikro}

Selanjutnya adalah melakukan pengamatan struktur mikro. Sebelum melakukan pengamatan, spesimen harus melewati beberapa tahap. Pertama spesimen harus dipoles menggunakan amplas menggunakan ampelas dengan tingkat kekasaran mulai dari 100-1500. Setelah dipoles menggunakan amplas, spesimen akan dipoles menggunakan kain beludru dengan mengoleskan autosol ke permukaan sampai mengkilat dan tidak ada guratan. Langkah terakhir adalah melakukan proses etsa, dimana proses etsa menggunakan campuran asam nitrat $\left(\mathrm{HNO}_{3}\right)$ sebanyak 4\% dan alcohol 96\%. Proses etsa dilakukan dengan mencelupkan bagian yang permukaan spesimen yang akan diamati dengan rentang waktu 20-25 detik. Permukaan yang telah dietsa selanjutnya akan dilakukan pengamatan menggunakan mikroskop optik dengan perbesaran 500 kali.

\section{HASIL DAN PEMBAHASAN}

\section{a. Uji Kekerasan Rockwell.}

Pengujian kekerasan ini menggunakan metode uji kekerasan Rockwell skala B dengan beban total 100 kgf. Perbedaan tingkat kekerasan pada permukaan baja karbon rendah setelah dilakukan hardfacing kemudian di heat treatment dapat dilihat pada tabel - tabel dan grafik dibawah ini.
Tabel 3.1 Nilai kekerasan material induk

\begin{tabular}{|c|c|c|}
\hline Penjejakan & $\begin{array}{c}\text { Nilai Kekerasan } \\
\text { (HRB) }\end{array}$ & $\begin{array}{c}\text { Rata Rata } \\
\text { (HRB) }\end{array}$ \\
\hline 1 & 52.5 & \multirow{2}{*}{5} \\
\hline 2 & 56.7 & \multirow{2}{*}{5} \\
\hline 3 & 56.4 & \\
\hline 4 & 52.3 & \\
\hline 5 & 54.7 & \\
\hline
\end{tabular}

Tabel 3.2 Nilai kekerasan laju aliran gas 1 1/m non treatment

\begin{tabular}{|c|c|c|}
\hline Penjejakan & $\begin{array}{c}\text { Nilai Kekerasan } \\
\text { (HRB) }\end{array}$ & $\begin{array}{c}\text { Rata Rata } \\
\text { (HRB) }\end{array}$ \\
\hline 1 & 80.2 & \multirow{2}{*}{8} \\
\hline 2 & 82.3 & \multirow{2}{*}{82} \\
\hline 3 & 82.6 & \\
\hline 4 & 82.6 & \\
\hline 5 & 80.5 & \\
\hline
\end{tabular}

Tabel 3.3 Nilai kekerasan laju aliran gas $1 \mathrm{~L} / \mathrm{m}$ heat treatment

\begin{tabular}{|c|c|c|}
\hline Penjejakan & $\begin{array}{c}\text { Nilai Kekerasan } \\
\text { (HRB) }\end{array}$ & $\begin{array}{c}\text { Rata Rata } \\
\text { (HRB) }\end{array}$ \\
\hline 1 & 86.5 & \multirow{2}{*}{} \\
& \multirow{2}{*}{88} \\
\hline 2 & 88.2 & \\
\hline 4 & 84.0 & \\
\hline 5 & 86.2 & \\
\hline
\end{tabular}

Tabel 3.4 Nilai kekerasan laju aliran gas $3 \mathrm{~L} / \mathrm{m}$ non treatment

\begin{tabular}{|c|c|c|}
\hline Penjejakan & $\begin{array}{c}\text { Nilai Kekerasan } \\
\text { (HRB) }\end{array}$ & $\begin{array}{c}\text { Rata Rata } \\
\text { (HRB) }\end{array}$ \\
\hline 1 & 79.8 & \multirow{2}{*}{7} \\
\hline 2 & 78.2 & \multirow{2}{*}{76} \\
\hline 3 & 78.3 & \\
\hline 4 & 75.5 & \\
\hline 5 & 69.7 & \\
\hline
\end{tabular}

Tabel 3.5 Nilai kekerasan laju aliran gas $3 \mathrm{~L} / \mathrm{m}$ heat treatment

\begin{tabular}{|c|c|c|}
\hline Penjejakan & $\begin{array}{c}\text { Nilai Kekerasan } \\
\text { (HRB) }\end{array}$ & $\begin{array}{c}\text { Rata Rata } \\
\text { (HRB) }\end{array}$ \\
\hline 1 & 81.8 & \multirow{2}{*}{8} \\
\hline 2 & 85.4 & \multirow{2}{*}{83} \\
\hline 3 & 81.6 & \\
\hline 4 & 83.9 & \\
\hline 5 & 80.0 & \\
\hline
\end{tabular}

Tabel 3.6 Nilai kekerasan laju aliran gas $5 \mathrm{~L} / \mathrm{m}$ non treatment

\begin{tabular}{|c|c|c|}
\hline Penjejakan & $\begin{array}{c}\text { Nilai Kekerasan } \\
\text { (HRB) }\end{array}$ & \multirow{2}{*}{$\begin{array}{c}\text { Rata Rata } \\
\text { (HRB) }\end{array}$} \\
\hline 1 & 66.9 & \multirow{2}{*}{6} \\
\hline 2 & 66.8 & \multirow{2}{*}{65} \\
\hline 3 & 66.8 & \\
\hline 4 & 63.8 & \\
\hline 5 & 62.8 & \\
\hline
\end{tabular}

Tabel 3.7 Nilai kekerasan laju aliran gas $5 \mathrm{~L} / \mathrm{m}$ heat treatment

\begin{tabular}{|c|c|c|}
\hline Penjejakan & $\begin{array}{c}\text { Nilai Kekerasan } \\
\text { (HRB) }\end{array}$ & $\begin{array}{c}\text { Rata Rata } \\
\text { (HRB) }\end{array}$ \\
\hline 1 & 63.7 & \multirow{2}{*}{70} \\
\hline 2 & 62.9 & \multirow{2}{*}{70} \\
\hline 3 & 73.8 & \\
\hline 4 & 67.2 & \\
\hline 5 & 82.6 & \\
\hline
\end{tabular}




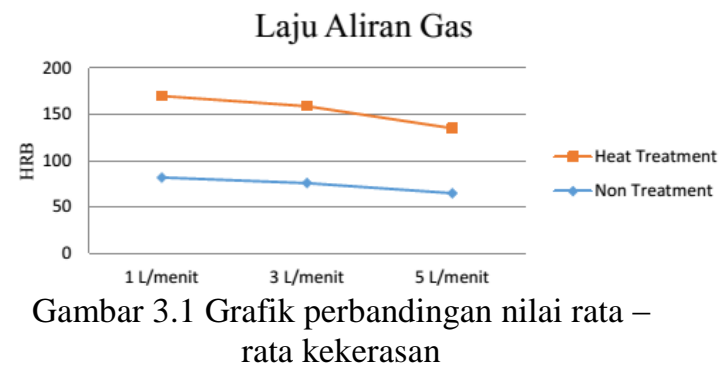

b. Struktur Mikro Base Material Non Treatment pada Plat 1

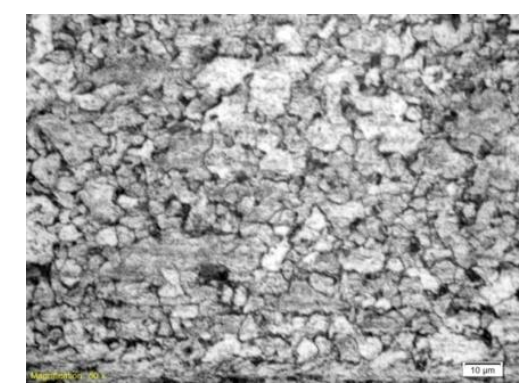

Gambar 3.2Struktur Mikro Logam Induk Non Treatment Plat 1

Pada gambar diatas, ditemukan struktur mikronya yaitu ferrit. Kemudian terdapat pearlite yang berwarna hitam pada batasan butir ferrit, namun bentuknya tidak beraturan.Struktur ferrit dan pearlit terbentuk akibat proses panas pada saat pengelasan yang mencapai suhu austenite kemudian terjadi pendingan yang cenderung lambat.

\section{c. Struktur Mikro Logam Pengisi Non Treatment pada Plat 1}

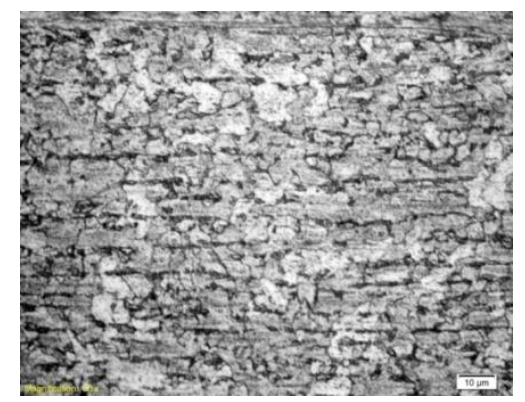

Gambar 3.3 Struktur Mikro Logam Pengisi Non Treatment pada Plat 1

Pada gambar diatas, stuktur yang terlihat juga didominasi oleh ferrit dan pearlite. Tidak berbeda dengan logam induk, struktur ferrit dan pearlite terbentuk karena terjadi pendinginan yang cenderung lambat. d. Struktur Mikro Logam Induk Non Treatment pada Plat 3

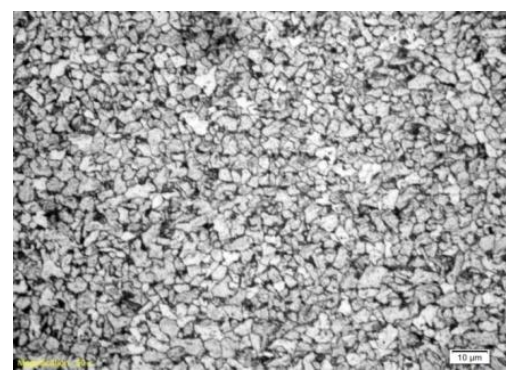

Gambar 3.4. Struktur Mikro Logam Induk Non Treatment pada Plat 3

Pada gambar diatas dapat dilihat struktur ferrit dan pearlite, namun ferrit terlihat lebih mendominasi dan menyebar diseluruh permukaan. Terlihat juga struktur pearlite dengan bentuk yang tidak beraturan berada diantara batas butir ferrit. Fasa ini terbentuk dikarenakan proses pendinginan yang lambat.

e. Struktur Mikro Logam Pengisi Non Treatment pada Plat 3

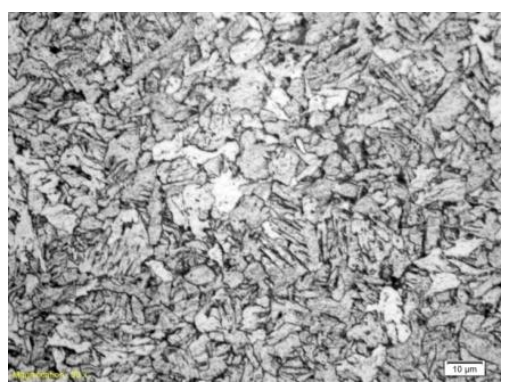

Gambar 3.5 Struktur Mikro Logam

Pengisi Non Treatment pada plat 3

Pada Gambar di atas Struktur mikro didaerah logam pengisi sudah membentuk struktur martensite. Hal ini disebabkan karena adanya pendingan secara kontinyu yang relatif cepat.

\section{f. Struktur Mikro Logam Induk Non Treatment pada Plat 5}

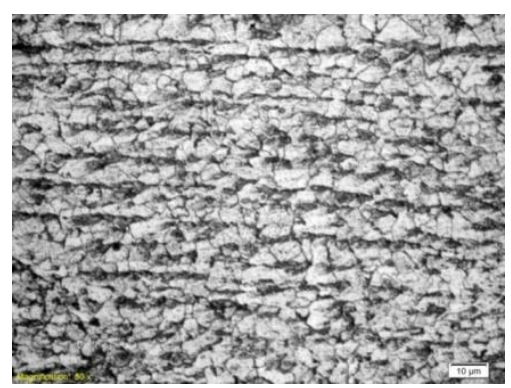

Gambar 3.6 Struktur Mikro Logam Induk Non Treatment pada Plat 5 
Pada gambar di atas struktur yang terlihat lebih dominan adalah strukstur ferrit, dimana strukstur tersebut menyebar ke seluruh permukaan. Diantara batas butir ferrit terdapat struktur pearlite yang berwarna hitam. Hal ini terjadi karena proses pendinginan terjadi dalam waktu yang relatif lama.

\section{g. Struktur Mikro Logam Pengisi Non} Treatment pada Plat 5

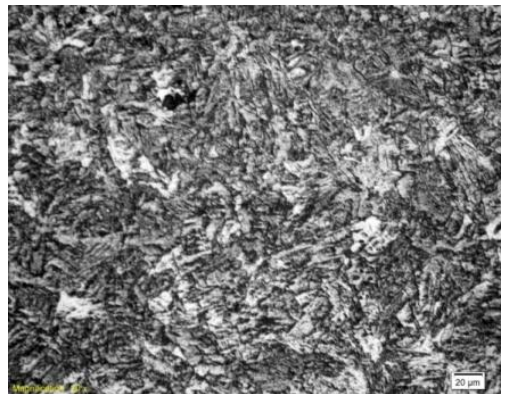

Gambar 3.7 Struktur Mikro Logam Pengisi Non Treatment pada Plat 5

Pada Gambar di atas struktur yang terlihat dominan adalah martensit. Struktur ini tersebar merata ke seluruh permukaan. Hal ini terbentuk karena proses pendinginan dari fasa autenite yang berlangsung dalam waktu yang cepat.

\section{h. Struktur Mikro Logam Induk Heat} Treatment pada Plat 1

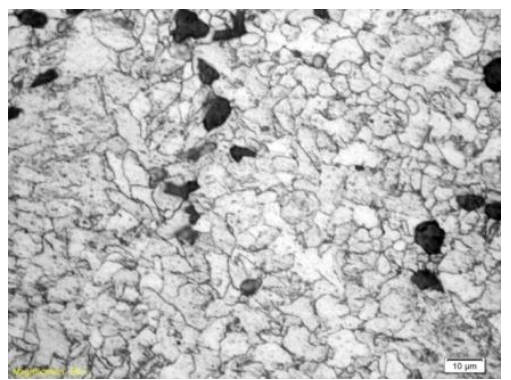

Gambar 3.8 Struktur Mikro Logam Induk Heat Treatmentpada Plat 1

Pada gambar di atas terlihat struktur yang mendominasi adalah struktur ferrit yang menyebar ke seluruh permukaan. Butirannya terlihat besar, hal ini terjadi karena proses pendinginan yang berlangsung lambat. i. Struktur Mikro Logam Pengisi Heat Treatment pada Plat 1

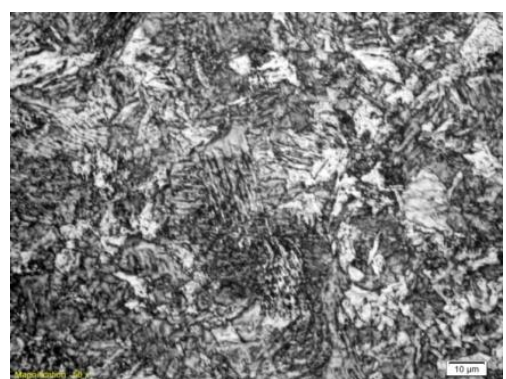

Gambar 3.9 Struktur Mikro Logam Pengisi Heat Treatmentpada Plat 1

Pada gambar di atas struktur yang terlihat adalah martensit, struktur ini masih mendominasi. Struktur ini terbentuk karena proses pendingan dari fasa austenite yang berlangsung cepat.

j. Struktur Mikro Logam Induk Heat Treatmentpada Plat 3

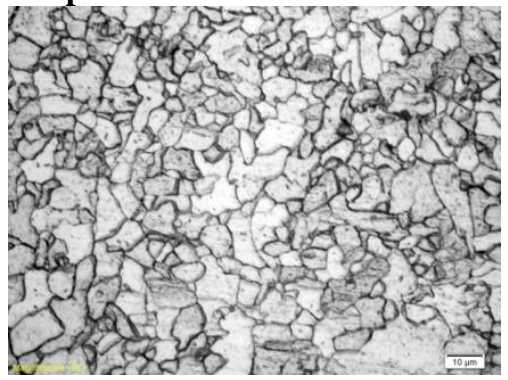

Gambar 3.10 Struktur Mikro Logam Heat Treatmentpada Plat 3

Pada Gambar di atas dapat dilihat struktur yang terbentuk adalah struktur ferrit. Struktur ini terlihat mendominasi serta memiliki ukuran butir yang besar. Hal ini terjadi karena proses pendinginan yang terjadi berlangsung dalam waktu yang lambat.

k. Struktur Mikro Logam Pengisi Heat Treatment pada Plat 3

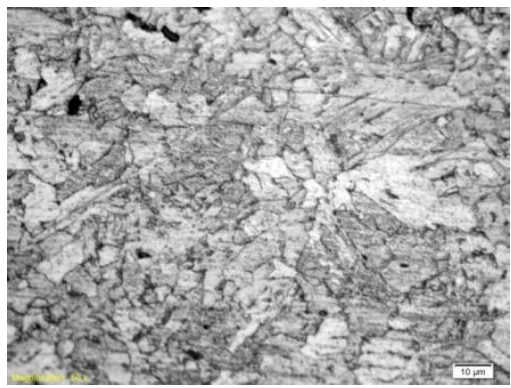

Gambar 3.11 Struktur Mikro Logam Pengisi Heat Treatmentpada Plat 3 
Pada Gambar di atas dapat dilihat struktur yang tampak adalah struktur martensit. Struktur ini terbentuk karena pada saat proses pendinginan dalam waktu yang cepat.

1. Struktur Mikro Logam Induk Heat Treatment pada Plat 5

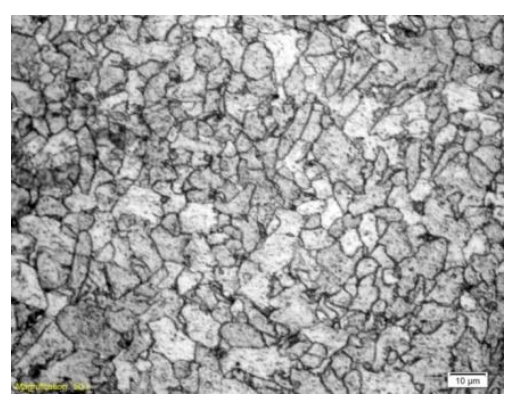

Gambar 3.12 Struktur Mikro Logam Induk Heat Treatmentpada Plat 5

Pada Gambar di atas dapat dilihat struktur yang tampak adalah struktur ferrit yang mendominasi ke seluruh bagian. Struktur ini terbentuk karena pada saat proses pendinginan terjadi dalam waktu yang lambat.

m. Struktur Mikro Logam Pengisi Heat Treatmentpada Plat 5

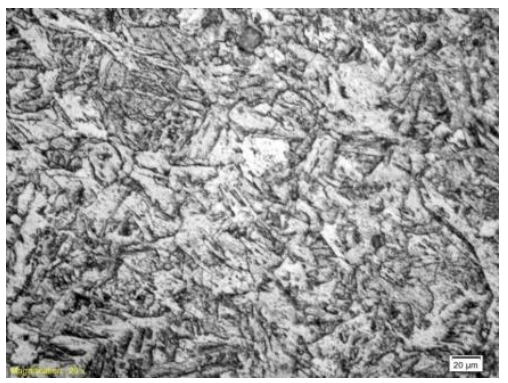

Gambar 3.13 Sruktur Mikro Logam Pengisi Heat Treatmentpada Plat 5

Pada Gambar di atas dapat dilihat struktur yang tampak adalah struktur martensit yang mendominasi ke seluruh bagian. Struktur ini terbentuk karena pada saat proses pendinginan dari fasa austenite terjadi dalam waktu yang cepat.

\section{KESIMPULAN}

Setelah dilakukan pengujian mekanik berupa pengujian kekerasan serta uji foto mikro baja karbon rendah. Didapatkan kesimpulan sebagai berikut:

1. Nilai kekerasan lapisanhardfacing tanpa diberikan heattreatment dengan laju aliran gas 1 liter/menit sebesar $82 \mathrm{HRB}$, dengan laju aliran gas 3 liter/menit sebesar 76 HRB, dengan laju aliran gas 5 liter/menit sebesar 65 HRB.

2. Nilai kekerasan lapisan hardfacing yang diberikan heattreatment dengan laju aliran gas 1 liter/menit sebesar $88 \mathrm{HRB}$, dengan laju aliran gas 3 liter/menit sebesar $83 \mathrm{HRB}$, dengan laju aliran gas 5 liter/menit sebesar 70 HRB.

\section{REFERENSI}

Amanto, H.dan Daryanto.(2006). Ilmu Bahan.Jakarta: Bumi Aksara.

Dadang.(2013). Teknik Las GTAW. Jakarta: Kementrian Pendidikan dan Kebudayaan.

Digambar, B., \& Choudhary, D. (2014). A Review Paper On Hardfacing Processes , Materials , Objectives and Applications. International Journal of Science and Research (IJSR), 3(6), 2400.

Eddy. 2014. Materi Uji Kekerasan dan Impak.http://eddme27.blogspot.co.id/2014/1 1/bab-i-pendahuluan-1.html (10 April 2017)

Kenchi Reddy, K.M. \& Jayadeva, C.T..(2012). An Experimental Study on the Effect of Microstructure on Wear Behavior of $\mathrm{Fe}-\mathrm{Cr}$ C Hardfacing Alloys. BonfringInternational Journal of Industrial Engineering and Management Science. Vol. 2,No. 1

Nikko Steel.(2009). Manufacturers Of A Diverse Range Of Advanced Welding Consumables. Rev 1.No.114.

Purwaningrum, Y.(2006). Karakterisasi Sifat Fisis dan Mekanis Sambungan Las SMAW Baja A-287 Sebelum dan Sesudah PWHT. Jurnal Teknoin, Vol 11,No.3.

Sahni, S., \& Singh, B.(2016). A Review of Hardfacing and Wear Reducing Techniques on Industrial Valves. International Journal ofResearch in Engineering \& Technology. Vol 4,23.

Wiryosumarto, H., \& Okumura, T.(2000). Teknologi Pengelasan Logam. Jakarta: Pradnya Paramadina 